\title{
Effect of aqueous root extract of Cynodon dactylon on the hemolytic activity of cardiotoxins from Indian cobra (Naja naja)
}

\author{
Suvathika Gnanaselvan, Thirunavukkarasu Sivaraman* \\ Drug Design and Discovery Lab, Department of Biotechnology, Karpagam Academy of Higher Education (Deemed to be University), \\ Coimbatore 641021, India.
}

\begin{tabular}{l}
\hline ARTICLE INFO \\
\hline Received on: $28 / 09 / 2019$ \\
Accepted on: $22 / 12 / 2019$ \\
Available online: 05/03/2020
\end{tabular}

\section{Key words:}

Antivenom, Cynodon

dactylon, hemolysis,

molecular docking,

phytochemicals.

\begin{abstract}
Snake venoms are a complex blend of enzymes and proteins/peptides depicting diverse pharmacological properties. Snakebite envenomation causes considerable morbidity and mortality worldwide, especially in rural regions. At present, the only available remedy for snakebite is polyvalent antivenoms and the antivenoms are shown to develop adverse effects such as anaphylaxis and pyrogen reactions. In the present study, we have examined antihemolytic activity of aqueous root extract of Cynodon dactylon against cardiotoxins belonging to three-finger toxin family of the Indian cobra crude venom. The aqueous root extract of the Cynodon dactylon was found to have remarkable antihemolytic potential against the crude venom as probed by in vitro assay. In this background, the phytochemicals present in the Cynodon dactylon extract were delineated using mass spectrometry data obtained for the extract and the compounds were then subjected to high-throughput virtual screening. A comprehensive analysis of the molecular docking data paved a way to identify a few lead antihemolytic chemical compounds from the plant extract. Scopes to explore structural determinants for the interaction between the chemical molecules and target protein toxins at high resolutions have also been discussed.
\end{abstract}

\section{INTRODUCTION}

Snakes are elongated and limbless reptiles and are distributed all over the world, mainly in Asia, Africa, and Australia (Bansode et al., 2016). There are about 3,783 species of snakes in the world and about 600 of them were found to be venomous snakes (https:/www.who.int/). The venomous snakes found in India are spectacled cobra (Naja naja), Common krait (Bungarus caeruleus), Saw scaled viper (Echis carinatus), and Russell's viper (Daboia russelii), which are generally referred as "Big four" venomous snakes of India (Anita et al., 2012). In general, irrespective of the snake species, snake venoms are a complex blend of tens of enzymatic and non-enzymatic proteins having diverse pharmacological activities (Bawaskar and Bawaskar,

\section{${ }^{*}$ Corresponding Author}

Thirunavukkarasu Sivaraman, Drug Design and Discovery Lab, Department of Biotechnology, Karpagam Academy of Higher Education (Deemed to be University), Coimbatore 641021, India.

E-mail:eazhilarasen@yahoo.com
2015). Snakebite envenomation causes considerable morbidity and mortality to animals and humans. It has been estimated that about five million people are reported as victims of snakebites every year, which includes an estimated 2.4 million envenoming and about 125,000 deaths worldwide (Kasturiratne et al., 2008). As per the literature reports, there were nearly 81,000 envenoming and 11,000 deaths annually in India itself. The only treatment available to date for snakebite envenomation is polyvalent antiserum treatment. However, there are several disadvantages in the antiserum treatment: having high quantity/quality and storage systems of the antiserum are technically challenging tasks; the antiserum is costprotective from economical standpoints and in terms of clinical concerns, the antiserum causes side effects such as anaphylaxis and pyrogen to the treatment of snakebite patients (Félix-Silva et al., 2017; Guerranti et al., 1999; Mustafa et al., 2016).

To overcome the limitations of the antiserum treatments, phytochemicals comprising components such as alkaloids, steroids, enzymes, peptides, and glycosides have been explored against snake venoms by many research groups worldwide (Gomes et al., 2010). The plants possessing antisnake venom activity comes under the families such as Fabaceae, Euphorbiaceae, 
Apocynaceae, Lamiaceae, Asteraceae, Malvaceae, Melastomaceae, and Sapindaceae (Félix-Silva et al., 2017). The main advantages of using antivenom compounds from plants are as follows: easy accessibility, stability at ambient conditions, cost-effective, neutralizes several toxins, and depicting no side effects (FélixSilva et al., 2017). In this context, we have herein demonstrated the antihemolytic activities of Cynodon dactylon as studied by in vitro and in silico studies. The Cynodon dactylon (belongs to the family Poaceae) is a favorable herb in Ayurveda and is typically known by several names like Bermuda grass, Bahama grass, Couch grass, Devil grass, and Aruvam-pillu (Tamil name). The various forms of the grass juices are used (either externally or internally) to treat diseases such as nasal bleeding, headache, epilepsy, piles, diarrhea, kidney stones, ulcer, and cancers (Rita et al., 2012).

\section{MATERIALS AND METHODS}

\section{Collection and extraction of Cynodon dactylon}

Roots of the Cynodon dactylon were collected from paddy fields in Sathyamangalam of Coimbatore districts, Tamil Nadu. About $1 \mathrm{~kg}$ of freshly collected roots was washed in running water and shade dried for about two weeks at ambient conditions. The well-dried roots were then pulverized into coarse powder and $200 \mathrm{~g}$ of the coarse powder was soaked in $1,000 \mathrm{ml}$ of double deionized water with $0.05 \%$ (v/v) chloroform for 48 hours with an intermittent mixing for every 1 hours. The mixture was then filtered using Grade-1 Whatman filter paper and the filtrate obtained was subsequently subjected to solvent evaporation at 343 $\mathrm{K}$ for 8 hours and the resultant material was kept in an air-tight container and stored at $278 \mathrm{~K}$ till the material was needed to use for the present antitoxicity studies.

\section{Preparation of RBC solution and hemolytic assay}

About $9 \mathrm{ml}$ of fresh blood of healthy human beings (Blood samples were collected from three male students - whose ages were 20-23 - of Biotechnology Department of the authors of this article. Each candidate donated the blood only once for the experiments of the study and the procedure was guided and monitored by the pharmacist of the university. Moreover, prior approval (KAHE/ IAEC/2019/19-10/003) for the usages of human blood samples for the present research had been obtained from Institutional Animal Ethical committee) was collected in a test tube containing sodium citrate as an anticoagulant and then the blood sample was subjected to centrifugation at 1,000 rpm for 10 minutes to get pellet of the red blood cells (RBC), which was washed with phosphate buffer saline (PBS) for 2-3 times. The RBC solution was prepared by dissolving the RBC pellet in $18 \mathrm{ml}$ of the PBS. The Minimal Haemolytic Dose (MHD) was determined by in vitro direct hemolytic activity of Naja naja venom (lyophilized venom of Naja naja was purchased from "The Irula Snake-Catchers Industrial Cooperative Society (ISCICS)" Mamallapuram, Tamil Nadu). To $1 \mathrm{ml}$ of the RBC solution, $2 \mathrm{ml}$ of toxin solution (containing varied concentration of the crude venom) was added in an individual experiment and the mixtures were incubated at $310 \mathrm{~K}$ for 30 minutes. Then, the mixtures were subjected to ice-cold incubation immediately to stop hemolysis reaction and the test samples were then subsequently centrifuged at 3,000 rpm for 15 minutes. The optical density of the supernatants collected from the samples was measured at 540 $\mathrm{nm}$ by UV-Visible spectroscopy (Shimadzu UV - 2450). The
MHD of the crude snake venom was calculated from the data as described elsewhere (Reddi et al., 2014). The MHD of the crude venom was treated with PBS containing varying concentration of Cynodon dactylon extract for 15 minutes at ambient condition and then the mixtures were incubated with $1 \mathrm{ml}$ of RBC solution for 30 minutes at $310 \mathrm{~K}$. The inhibition potential of aqueous root extract of the Cynodon dactylon against the hemolytic toxins of the crude venom was calculated by measuring the optical density for the supernatants obtained from the test samples at $540 \mathrm{~nm}$ as described in the literature (Reddi et al., 2014).

\section{Gas chromatography-mass spectrometry (GC-MS) analysis}

The bioactive components in the aqueous root extract of Cynodon dactylon were analyzed by GC-MS in order to identify the compounds inhibiting the snake venom cardiotoxins. About $100 \mu \mathrm{g}$ of the aqueous root extract was dissolved in $2.0 \mathrm{ml}$ of analytical grade methanol and the mixture was filtered using 0.22 $\mu \mathrm{M}$ nylon syringe filter and resultant transparent solution was used as a sample for the GC-MS experiments (Thermo scientific Dual Stage Quadrupole (DSQ) II quadruple mass spectrometer equipped with $5 \%$ phenyl-methyl silicon fused capillary column). Technical parameters set for the GC-MS were as shown herein: splitless mode; electron impact mode at $70 \mathrm{eV}$; base mode injector; syringe volume $10 \mu \mathrm{l} ; 30 \mathrm{~mm}$ of vial depth; maximum and initial temperatures were $350^{\circ} \mathrm{C}$ and $110^{\circ} \mathrm{C}$, respectively; scan rate was $10^{\circ} \mathrm{C} /$ minute; mass detection range was set to be from 50 to 650 Da. The compounds present in the plant extract were discerned by correlating the experimental data with that of chemical molecules from small molecular databases such as National Institute of Standards and Technology (NIST) and PubChem (Boti et al., 2005).

\section{Molecular dockings and interaction analysis}

The amino acid sequence of the cardiotoxin 1 from Naja naja was obtained from UniProt database (http://www.uniprot. org) and overall tertiary structures of the protein were homology modeled using Modeller9V8 computational tool. The molecular modeling and validations of the modeled 3D structures of the cardiotoxin 1 have already been elaborately described elsewhere by the author of the present work (Gorai et al., 2015; Gorai and Sivaraman, 2017; Kumar et al., 1997). The structures of the 46 chemical molecules present in the root extract of the Cynodon dactylon were retrieved from the NIST/PubChem database and the structures were then energy minimized and saved in various structural file formats such as sdf or pdb or mol2 that are compatible for docking simulations. Structural interactions between the chemical compounds and the cardiotoxin 1 were simulated through an unbiased molecular docking strategy. The population and generations for the simulation studies were set as 200 and 70, respectively. On the basis of docking energies, top-ten compounds were identified and non-bonding interactions of the compounds with the cardiotoxin 1 were analyzed using molecular visualization tools such as PyMol 0.99rc6 and Schrödinger suite 9.3, USA (Sivakumar et al., 2013).

\section{RESULTS AND DISCUSSION}

Antivenin activities of about 15 different medicinal plants against Indian cobra venom have been reported to date in the literature to the best of our knowledge (Durairaj et al., 2014; Gopi et al., 2011; 2014; King and Balasubramanian, 2015; 
Meenatchisundaram et al., 2009; Meenatchisundaram and Michael, 2010; Nisha et al., 2018; Raghavamma et al., 2016; Rajesh et al., 2017; Reddi et al., 2014; Shrikanth et al., 2016; Sivaraman et al., 2013; 2017; Suresh and Balasubramanian, 2016; Yedelli et al., 2018). However, comparative analyses of the outcomes were not a straightforward task as the studies are differing from one another in many facets: different solvent extracts of various parts of the plants have been used; most of the studies have been carried out either at in vitro or at in vivo levels only; different animal models and different $\mathrm{LD}_{50}$ values have been used; active principals of the plant extracts have been identified only in some cases; treatment types and modes of administration of the extracts were not same in all cases. Meantime, some plant extracts, for instance, Aristolochia bracteolate, Mimosa pudica, and Prosopis cineraria, have been reported to possess remarkable protection against the Indian cobra venom at high confidential levels (Meenatchisundaram et al., 2009; Sivaraman et al., 2013). In this background, we have herein demonstrated the antihemolytic activity of aqueous root extract of the Cynodon dactylon against cardiotoxins of Naja naja venom.

The aqueous root extract of the Cynodon dactylon was prepared as described in the methods section and the dried phytochemical mixture was directly used for all the studies unless otherwise mentioned. The MHD of the crude venom was found to be $1.0 \mathrm{mg} / \mathrm{ml}$ and hence, the effect of the plant extract was examined against the concentration throughout the hemolytic experiments. On the other hand, the aqueous root extract of the Cynodon dactylon was varied from 10 to $1,500 \mu \mathrm{g} / \mathrm{ml}$ and overall percentage inhibition of the Cynodon dactylon against the cardiotoxins of the cobra venom is depicted in Figure 1. A quick inspection of the figure suggests that $200 \mu \mathrm{g} / \mathrm{ml}$ of the extract could inhibit about $80 \%$ hemolytic activity of the crude venom. Moreover, as inferred from Figure 1, the percentage inhibitions were found to be around $85 \%$ (ranging from $84.3 \%$ to $90.6 \%$ ) even up to the extract concentration of $1,500 \mu \mathrm{g} / \mathrm{ml}$ implying that the amount of active principles present in the $200 \mu \mathrm{g} / \mathrm{ml}$ of the extract could be presumably good enough to almost neutralize the hemolytic factor, cardiotoxins, of the crude venom. In this context, about $20 \%$ hemolytic activity of the crude venom treated even at high extract concentration of $1,500 \mu \mathrm{g} / \mathrm{ml}$ is perplexing and the phenomena may probably be attributed to any one of the following two reasons: (i) the phytochemicals of the Cynodon dactylon may not be efficient to fully inhibit certain cardiotoxins of the crude venom as there are many types of the cardiotoxins such as $\mathrm{P}-/ \mathrm{S}-/$ SL-/SK-type cardiotoxins reported to date in the literature (Kumar et al., 1997; Sivaraman et al., 1997); (ii) the snake venom may contain some other (unknown to date) hemolytic factors other than the cardiotoxins and those toxins may not be inhibited by the phytochemicals present in the Cynodon dactylon extract.

The GC-MS analysis of plant extract indicated the presence of quite a large number of bioactive compounds in the aqueous root extract of Cynodon dactylon. The GC chromatogram displayed 15 peaks (data not shown) and each peak may be a representation of one or more compounds. Of about 280 compounds that were roughly identified at the primary NIST database screening, 46 unique chemical compounds could be promisingly sorted out on the basis of ionization patterns of the respective compounds and the compound names are listed out in Table 1. The three-dimensional structures of the 46 molecules were constructed, energy minimized, and subjected to highthroughput virtual screening through molecular docking technique to rationalize prototype inhibitors to the cardiotoxins of Naja naja (Indian Cobra).

The cardiotoxins belong to a class of all beta-sheet proteins. The number of amino acids present in the primary sequences of the cardiotoxins reported to data is shown to vary from 59 to 62 (Gorai and Sivaraman, 2017). Hemolytic activities of the cardiotoxins have been well-characterized and the data suggested that cardiotoxins are drastically differing from one another in the activities. Despite the lack of authentic correlations between their 3D folds and activities, the cardiotoxins are classified either as a P-type or S-type protein toxins. The P-type cardiotoxins possess invariably "proline" residue at position 30 , whereas the S-type cardiotoxins possess invariably "Serine" at position 28 in their respective linear polypeptide chain (Kumar et al., 1997;

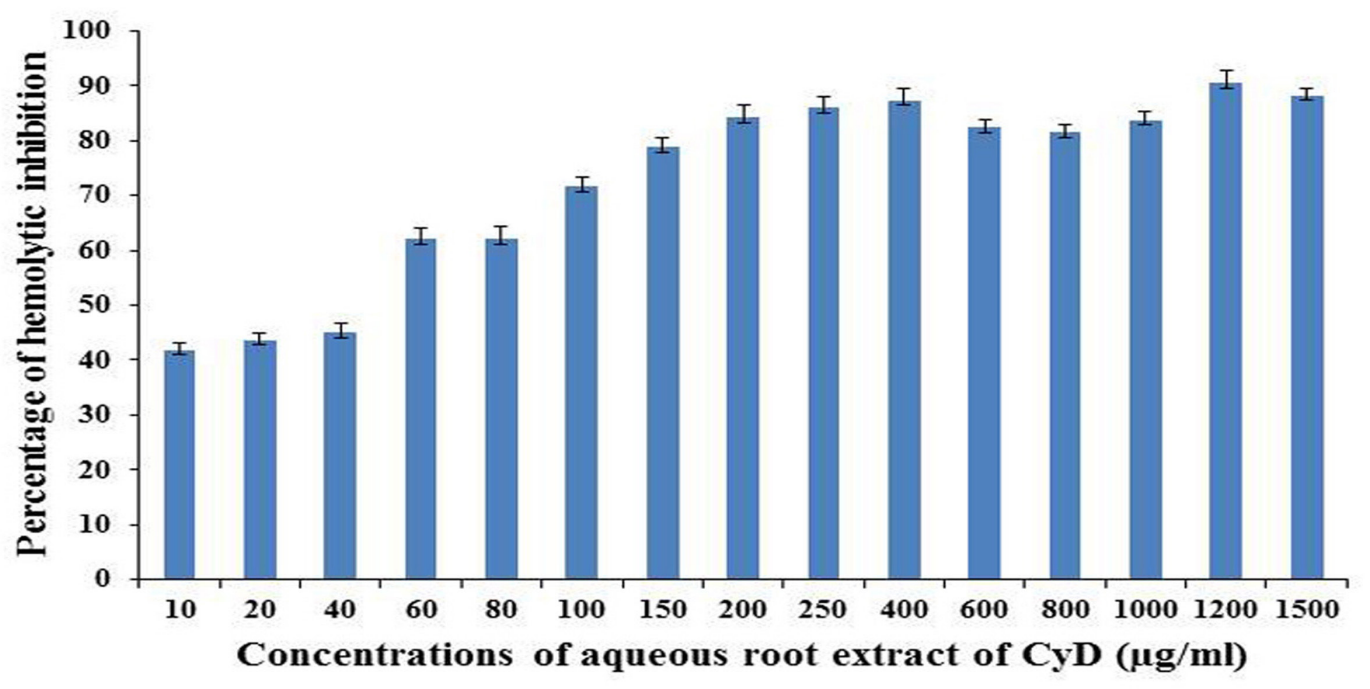

Figure 1. Effects of aqueous root extract of the Cynodon dactylon on human RBC are shown with respect to the extract concentration $(\mathrm{mg} / \mathrm{ml})$ at ambient experimental conditions. Each data point represents mean \pm standard deviation of three independent experiments. 
Table. 1. List of compounds identified in the aqueous root extract of Cynodon dactylon by GC-MS analysis. Retention time (RT), peak area and probability, which indicates the matching of the GC-MS data obtained for the compounds under interest in the present study to that reported for the corresponding compounds in the NIST database.

\begin{tabular}{|c|c|c|c|c|}
\hline S. No. & Names of phytochemicals present in the Cynodon dactylon aqueous root extract & RT (Minutes) & Peak area $(\%)$ & Probability \\
\hline 1 & 1-chloro-2-nitro-Ethane & 1.53 & 3.6 & 46.2 \\
\hline 2 & Propanoic acid, 2-chloro-, methyl ester & 2.08 & 2.3 & 20.6 \\
\hline 3 & 1-Chloro-2-methylpropyl chloroformate & 2.08 & 2.3 & 19.0 \\
\hline 4 & 9-Octadecenoic acid, (2-phenyl-1,3-dioxolan-4-yl)methyl ester & 2.75 & 10.3 & 51.0 \\
\hline 5 & $\delta$-Gala-l-ido-octonic amide & 2.75 & 10.3 & 6.8 \\
\hline 6 & 1-Gala-1-ido-octonic lactone & 2.75 & 10.3 & 3.6 \\
\hline 7 & Desulphosinigrin & 4.02 & 0.2 & 24.1 \\
\hline 8 & 4H-Pyran-4-one, 2,3-dihydro-3,5-dihydroxy-6-methyl & 4.34 & 8.2 & 27.6 \\
\hline 9 & 1,3-Diazacyclooctane-2-thione & 4.34 & 8.2 & 14.2 \\
\hline 10 & Acetic acid, 2,2'-[oxybis(2,1-ethanediyloxy)]bis- & 5.40 & 0.1 & 14.5 \\
\hline 11 & Octadecanoic acid, 3-hydroxy-, methyl ester & 5.67 & 0.04 & 17.4 \\
\hline 12 & Egtazic acid & 5.67 & 0.04 & 10.6 \\
\hline 13 & Pyrrolidine, 1-(1-oxo-2,5-octadecadienyl)- & 5.97 & 0.04 & 21.2 \\
\hline 14 & 12-Dimethylamino-10-oxododecanoic acid & 5.97 & 0.04 & 14.1 \\
\hline 15 & Ascaridole epoxide & 6.46 & 1.0 & 25.4 \\
\hline 16 & R-Limonene & 6.46 & 1.0 & 11.1 \\
\hline 17 & 6-Octadecynoic acid, methyl ester & 7.03 & 1.4 & 10.1 \\
\hline 18 & 2,4,7,9-Tetramethyl-5-decyn-4,7-diol & 7.60 & 3.4 & 21.4 \\
\hline 19 & Acetamide, N-methyl-N-[4-(3-hydroxypyrrolidinyl)-2-butynyl]- & 8.33 & 1.4 & 22.5 \\
\hline 20 & Phenol, 2,4-bis(1,1-dimethylethyl)- & 8.82 & 0.7 & 20.3 \\
\hline 21 & 2-Myristynoyl pantetheine & 9.19 & 0.5 & 21.2 \\
\hline 22 & 9,10-Secocholesta-5,7,10(19)-triene-1,3-diol, 25-[(trimethylsilyl)oxy]-, (3á,5Z,7E) & 9.19 & 0.5 & 12.2 \\
\hline 23 & Phen-1,4-diol, 2,3-dimethyl-5-trifluoromethyl- & 9.84 & 2.1 & 60.5 \\
\hline 24 & 1-(3-(Cyclohexylamino)propyl)guanidine & 10.60 & 1.6 & 19.4 \\
\hline 25 & Morphinan-4,5-epoxy-3,6-di-ol, 6-[7-nitrobenzofurazan-4-yl]amino- & 10.92 & 2.1 & 21.9 \\
\hline 26 & Digitoxin & 13.33 & 1.2 & 5.7 \\
\hline 27 & 9-Oximino-2,7-diethoxyfluorene & 13.80 & 0.8 & 16.7 \\
\hline 28 & 7,9-Di-tert-butyl-1-oxaspiro(4,5)deca-6,9-diene-2,8-dione & 14.18 & 1.2 & 85.7 \\
\hline 29 & Estra-1,3,5(10)-trien-17 $\alpha$-ol & 14.61 & 4.6 & 30.6 \\
\hline 30 & Dasycarpidan-1-methanol, acetate & 14.61 & 4.6 & 17.6 \\
\hline 31 & Cyclopropanedodecanoic acid, 2-octyl-, methyl ester & 15.36 & 0.5 & 18.6 \\
\hline 32 & Octadecanoic acid, 2-hydroxy-1,3-propanediyl ester & 17.99 & 1.5 & 14.5 \\
\hline 33 & 9,12,15-Octadecatrienoicacid,2-[(trimethylsilyl)oxy]-1-[[(trimethylsilyl)oxy]methyl]ethylester, (Z,Z,Z)- & 16.00 & 0.1 & 27.5 \\
\hline 34 & 9,12,15-Octadecatrienoic acid, 2,3-bis[(trimethylsilyl)oxy]propyl ester, (Z,Z,Z)- & 16.00 & 0.1 & 37.9 \\
\hline 35 & 1-Monolinoleoylglycerol trimethylsilyl ether & 20.01 & 0.9 & 7.8 \\
\hline 36 & Hexadecanoic acid, 1-(hydroxymethyl)-1,2-ethanediyl ester & 17.99 & 1.5 & 5.5 \\
\hline 37 & $\begin{array}{l}7 \alpha \mathrm{H} \text {-Cyclopenta[a]cyclopropa[f]cycloundecene- } 2,4,7,7 \alpha, 10,11 \text {-hexol, } 1,1 \alpha, 2,3,4,4 \alpha, 5,6,7,10,11,11 \alpha \text { - } \\
\text { dodecahydro-1,1,3,6,9-pentamethyl-,2,4,7,10,11-pentaacetate }\end{array}$ & 23.60 & 1.0 & 12.4 \\
\hline 38 & Hexasiloxane, $1,1,3,3,5,5,7,7,9,9,11,1$-dodecamethyl- & 24.78 & 0.04 & 6.0 \\
\hline 39 & Heptasiloxane, 1,1,3,3,5,5,7,7,9,9,11,11,13,13-tetradecamethyl- & 25.90 & 0.03 & 7.5 \\
\hline 40 & Octasiloxane, $1,1,3,3,5,5,7,7,9,9,11,11,13,13,15,15$-hexadecamethyl- & 25.90 & 0.03 & 34.4 \\
\hline 41 & $\alpha$-D-Glucopyranoside, O- $\alpha$-D-glucopyranosyl-(1.fwdarw.3)- $\alpha$-D fructofuranosy & 4.02 & 0.2 & 32.3 \\
\hline 42 & 2-Methyl-9- $\alpha$-d-ribofuranosylhypoxanthine & 6.46 & 1.0 & 25.4 \\
\hline 43 & Cyclopentaneethanol, 4-(acetyloxy)-2-[(acetyloxy)methyl]-á,3-dimethyl-, acetate & 7.60 & 3.4 & 13.4 \\
\hline 44 & $\alpha$-D-Galactopyranose,6-O-(trimethylsilyl)-, cyclic1,2:3,4-bis(butylboronate) & 10.92 & 2.1 & 17.2 \\
\hline 45 & 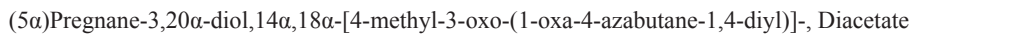 & 20.58 & 0.6 & 26.4 \\
\hline 46 & 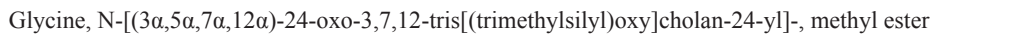 & 20.58 & 0.6 & 2.6 \\
\hline
\end{tabular}


Sivaraman et al., 1997). In this article, lead chemical inhibitors to the cardiotoxin 1 of Indian cobra venom have been reported and rationalized upon subjecting the 46 phytochemicals identified from the aqueous root extract of the Cynodon dactylon by means of molecular docking methods as described in the "Methods" section.

Of the 46 chemical compounds obtained from the Cynodon dactylon, the top-ten compounds exhibiting higher docking energies with the cardiotoxin 1 are listed below herein:

Compound 1: $7 \alpha \mathrm{HCyclopenta[a]cyclopropa[f]cycloundecene}$ 2,4,7,7a,10,11hexol, $1,1 \alpha, 2,3,4,4 \alpha, 5,6,7,10,11,1$ $1 \alpha$-dodecahydro1,1,3,6,9pentamethyl,2,4,7,10, 11 pentaacetate

Compound 2: $\alpha$-D-Glucopyranoside, $\mathrm{O}-\alpha$-D-glucopyranosyl(1.fwdarw.3)- $\alpha$-D-fructofuranosy

Compound 3: 9-Octadecenoicacid(2-phenyl1,3dioxolan4yl) methylester

Compound 4: 9,10-Secocholesta-5,7,10(19)-triene-1,3diol,25-[(trimethylsilyl)oxy]-,(3a,5Z,7E)

Compound.5: Octasiloxane,1,1,3,3,5,5,7,7,9,9,11,11,13,13,15, 15 hexadecamethyl

Compound 6: 9-Oximino2,7diethoxyfluorene

Compound 7: Hexadecanoicacid,1-(hydroxymethyl)-1,2ethanediylester

Compound 8: Hexasiloxane,1,1,3,3,5,5,7,7,9,9,11,11dodecamethyl

Compound 9: Heptasiloxane,1,1,3,3,5,5,7,7,9,9,11,11,13,13tetradecamethyl

Compound 10: Estra-1,3,5(10)-trien-17 $\alpha$-ol
Docking energies of the top-ten compounds with the cardiotoxin 1 were found to vary from -130.4 to $-8.4 \mathrm{~kJ} / \mathrm{mol}$. Moreover, on the basis of docking modes of the compounds, two distinct binding grooves on the surface of the cardiotoxin 1 were mapped out: one on the loop I (constituted by strand $1 \& 2$ ) and another one on the loop II (constituted by strand III \& IV). The former groove was mainly constituted by residues such as Lys2, Cys3, Leu6, Tyr11, and Arg58 and the latter groove was found to have residues such as Leu20, Tyr25, Lys30, Lys44, Lys50, and Glu52. Interestingly, of the ten chemical compounds mentioned above, other than the Compound 7, which was found to interact with the latter binding groove of the protein toxin, other 9 phytochemicals (compounds 1 - $6 \& 8$ - 10) showed binding interaction on the surface groove in the loop I of the cardiotoxin 1. Overall binding poses of the top-two phytochemicals (Compound $1 \&$ Compound 2) on the surface groove of the cardiotoxin 1 are depicted in Figure 2.

In conclusion, systematic analyzes as described above on the docking data of the cardiotoxin 1 and the phytochemicals revealed that Compound 1 and Compound 2 are reliable lead inhibitors to the snake venom cardiotoxins. The binding affinities and structural interactions of the lead compounds with the cardiotoxins can be studied at high resolution using techniques such as Isothermal Titration Calorimetry and Nuclear Magnetic Resonance Spectroscopic techniques, respectively in near future. Moreover, the two lead molecules identified in the present study may be used as seed molecules to design a few efficient antagonists, possibly unprecedented in the literature, to the cardiotoxins in the

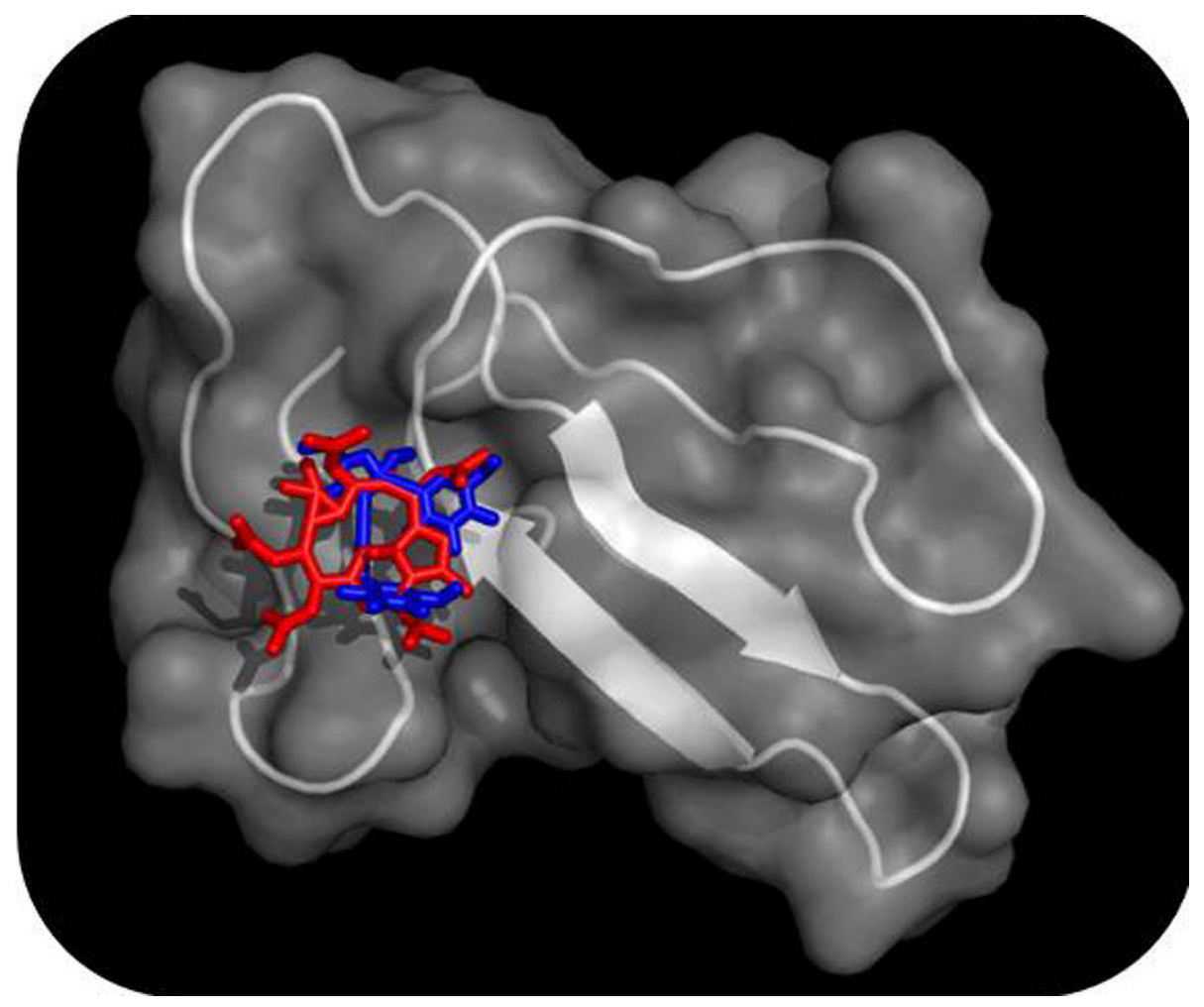

Figure 2. Binding modes of Compound 1 and Compound 2 on the surface groves of the cardiotoxin 1 from Indian cobra (Naja naja) are depicted as determined by molecular docking simulations. The cardiotoxin 1 is shown both in its surface and cartoon models (transparency was set to be 50\%) and the Compound 1 (red in color) and Compound 2 (blue in color) are shown in sticks models. 
near future and the cardiotoxin-inhibitors may presumably be subjected for evaluation through clinical studies in order to use them in the "combination therapy" of snakebite treatments.

\section{ACKNOWLKEDGEMENT}

The authors would like to express their sincere thanks to the management of "Karpagam Academy of Higher Education" for providing genuine supports to use "Central Instrumental Facility" and "Computational facility" to execute the experiments reported in the present research studies.

\section{CONFLICT OF INTEREST}

The authors declare that they have no conflicts of interest.

\section{REFERENCES}

Anita K, Shivaji CK, Kumar GV. Medicinal plants active against snake envenomation. Int J Res Ayurveda Pharm, 2012; 3(3):363-66.

Bansode SA, More VR, Mirza KA. A study on snakes from Mokhada and Jawhar (Dist. Palghar) Maharashtra, India. Int J Fauna Biol Stud, 2016; 3(5):103-15.

Bawaskar HS, Bawaskar PH. Snake bite poisoning. J Mahatma Gandhi Inst Med Sci, 2015; 20(1):5-14.

Boti JB, Koukoua G, N'Guessan TY, Muselli A, Bernardini AF, Casanova J. Composition of the leaf, stem bark and root bark oils of Isolonacooperi investigated by GC (retention index), GC-MS and 13C-NMR spectroscopy. Phytochem Anal, 2005; 16(5):357-63.

Durairaj B, Muthu S, Shreedhar K. In vitro antivenom and antioxidant potential of Vitex negundo leaves (green and blue) against Russell's viper (Daboia russelli) and Indian cobra (Naja naja) venom. Euro J Exp Bio, 2014; 4(4):207-19.

Félix-Silva J, Silva-Junior AA, Zucolotto SM, FernandesPedrosa MF. Medicinal plants for the treatment of local tissue damage induced by snake venoms: an overview from traditional use to pharmacological evidence. Evid Based Complement Alternat Med, 2017; Article ID 5748256:1-52.

Gomes A, Das R, Sarkhel S, Misra R, Mukherjee S. Herbs and herbal constituents active against snake bite. India J Exp Biol, 2010; 48(9):865-78.

Gopi K, Renu K, Jayaraman G. Inhibition of Naja naja venom enzymes by the methanolic extract of Leucas aspera and its chemical profile by GC-MS. Toxicol Rep, 2014; 1:667-73.

Gopi K, Renu K, Raj M, Kumar D, Muthuvelan B. The neutralization effect of methanol extract of Andrographis paniculata on Indian cobra Naja naja snake venom. J Pharm Res, 2011; 4(4):1010-12.

Gorai B, Prabhavadhni A, Sivaraman T. Unfolding stabilities of two structurally similar proteins as probed by temperature-induced and force-induced molecular dynamics simulations. J Biomol Struct Dyn, 2015; 33(9):2037-47.

Gorai B, Sivaraman T. Delineating residues for haemolytic activities of snake venom cardiotoxin 1 from Naja naja as probed by molecular dynamics simulations and in vitro validations. Int $\mathrm{J}$ Biol Macromol, 2017; 95:1022-36.

Guerranti R, Aguiyi JC, Leoncini R, Pagani R, Cinci G, Marinello E. Characterization of the factor responsible for the antisnake activity of Mucuna pruriens seeds. J Prev Med Hyg, 1999; 40:25-8.

Kasturiratne A, Wickremasinghe AR, de Silva N, Gunawardena NK, Pathmeswaran A, Premaratna R, Savioli L, Lalloo DG, de Silva HJ. The global burden of snakebite: a literature analysis and modelling based on regional estimates of envenoming and deaths. PLoS Med, 2008; 5(11):e218; doi:10.1371/journal.pmed.0050218

King ES, Balasubramanian M. Identification and characterization of bioactive compounds from Ruta graveolens L. leaf extract against Naja naja venom. Res J Pharm BiolChemSci,2015; 6(4):475-82.
Kumar TKS, Jayaraman G, Lee CS, Arunkumar AI, Sivaraman T, Samuel D, Yu C. Snake venom cardiotoxins-structure, dynamics, function and folding. J Biomol Struct Dyn, 1997; 15(3):431-63.

Meenatchisundaram S, Michael A. Antitoxin activity of Mucuna pruriens aqueous extracts against Cobra and Krait venom by in vivo and in vitro methods. Int J Pharm Tech Res, 2010; 2(1):870-74.

Meenatchisundaram S, Priyagrace S, Vijayaraghavan R, Velmurugan A, Parameswari G, Michael A. Antitoxin activity of Mimosa pudica root extracts against Naja naja and Bangarus caerulus venoms. Bangladesh J Pharmacol, 2009; 4(2):105-9.

Mustafa M, Fairrul K, Iiizam EL, Firdaus H, Nornazirah A, Mehvish $\mathrm{H}$. Neurotoxicity related to snakebite: treatment and prevention. $J$ Med Dent Sci Res, 2016; 3(10):20-5.

Nisha NC, Sreekumar S, Evans DA, Biju CK. In vitro and in silico validation of anti-cobra venom activity and identification of lead molecules in Aegle marmelos (L.) Correa. Curr Sci, 2018; 114(6):1214-21.

Raghavamma STV, Rao NR, Rao GD. Inhibitory potential of important phytochemicals from Pergularia daemia (Forsk.) chiov., on snake venom (Naja naja). J Genet Eng Biotechnol, 2016; 14(1):211-17.

Rajesh KS, Bharath BR, Rao CV, Bhat KI, Bhat KSC, Bhat P. Neutralization of Naja naja venom induced lethality, edema and myonecrosis by ethanolic root extract of Coix lacryma-jobi. Toxicol Rep, 2017; 4:637-45.

Reddi KVNR, Rajesh SS, Narendra K, Jangala S, Reddy PCO, Satya AK, Sivaraman T, Sekhar AC. In vitro anti-venom potential of various Jatropha extracts on neutralizing cytotoxic effect induced by phospholipase A2 of crude venom from Indian cobra (Naja naja). Bangladesh J Pharmacol, 2014; 9(1):22-8.

Rita P, Aninda M, Animesh DK. An updated overview on Cynodon dactylon (L.) Pers. Int J Res Ayurveda Pharm, 2012; 3(1):11-4.

Shrikanth VM, Janardhan B, More SS. In vitro neutralization of Eachis carinatus and Naja naja venom by Canthium parviflorum and its GC-MS analysis. Bangladesh J Pharmacol, 2016; 11(4):920-27.

Sivakumar D, Gorai B, Sivaraman T. Screening efficient BH3mimetics to hBcl-B by means of peptidodynmimetic method. Mol Bio Syst, 2013; 9(4):700-12.

Sivaraman T, Kumar TKS, Yang PW, Yu C. Cardiotoxin-like basic protein (CLBP) from Naja naja atra is not a cardiotoxin. Toxicon, 1997; 35(9):1367-71.

Sivaraman T, Rajesh SS, Elango V. In vivo studies on detoxifying actions of aqueous bark extract of Prosopis cineraria against crude venom from Indian cobra (Naja naja). Bangladesh J Pharmacol, 2013; 8(4):395400

Sivaraman T, Sreedevi NS, Meenatchisundaram S, Vadivelan R. Antitoxin activity of aqueous extract of Cyclea peltata root against Naja naja venom. Indian J Pharmacol, 2017; 49(4):275-81.

Suresh P, Balasubramanian M. Anti-venom activity of Camellia Sinensis L. leaves extract on Naja naja snake venom. Res J Pharm Biol Chem Sci, 2016; 7(4):384-91.

Yedelli к, Gottumukkala км, Mondi SR, Imaduddin, Permula PR. Antitoxin activity of different extracts of aerial parts of Tephrosia purpurea against Naja naja venom. J Pharm Res, 2018; 12(7):907-11.

How to cite this article:

Gnanaselvan S, Sivaraman T. Effect of aqueous root extract of Cynodon dactylon on the hemolytic activity of cardiotoxins from Indian cobra (Naja naja). J Appl Pharm Sci, 2020; 10(03):113-118 